\title{
Progress towards the eradication of Tsetse from the Loos islands, Guinea
}

\author{
Moise S Kagbadouno1, Mamadou Camara', Jérémy Bouyer ${ }^{2}$, Fabrice Courtin³ ${ }^{3}$ Mory F Onikoyamou ${ }^{4}$, \\ Chris J Schofield ${ }^{5}$, Philippe Solano ${ }^{3^{*}}$
}

\begin{abstract}
Background: The tsetse fly Glossina palpalis gambiensis is the main vector of sleeping sickness (Human African Trypanosomiasis - HAT) in West Africa, in particular in littoral Guinea where this disease is currently very active. The Loos islands constitute a small archipelago some $5 \mathrm{~km}$ from mainland Guinea, where G. p. gambiensis is well known as a nuisance and potential disease vector by inhabitants of the three main islands, Fotoba, Room, and Kassa. The National Control Program against HAT of Guinea has decided to eradicate tsetse in Loos islands in order to sustainably protect humans and economic activities. After baseline data collection, tsetse control began on the islands in 2006. On each of the three islands a specific combination of control methods was implemented according to the entomological situation found.

Results: Starting densities before control operations were 10, 3 and 1 tsetse/trap/day in Kassa, Room and Fotoba respectively, but by July 2010, tsetse were no longer caught in any of the sentinel traps used for monitoring. The reduction rate was faster where several control methods were implemented as a combination (impregnated traps and targets ITT, selective groundspraying, epicutaneous insecticide treatment of pigs, and impregnated fences around pig pens), whereas it was slower when ITT were used as the only control method.

Conclusions: This $100 \%$ suppression is a promising step in the eradication process, but G. p. gambiensis may still occur at very low, undetectable, densities on the archipelago. Next step will consist in assessing a 0.05 probability of tsetse absence to ascertain a provisional eradication status. Throughout these operations, a key factor has been the involvement of local teams and local communities without whom such results would be impossible to obtain. Work will continue thanks to the partners involved until total eradication of the tsetse on Loos islands can be declared.
\end{abstract}

\section{Introduction}

The Loos Islands form a small archipelago off the coast of Guinea-Conakry, some $5 \mathrm{Km}$ from the nearest mainland, which are home to some 8000 inhabitants. Tsetse (Glossina palpalis gambiensis VanderPlanck, 1949) were abundant on the three inhabited islands, Kassa, Fotoba and Room, representing a considerable nuisance to the local fishing communities and to tourism, as well as affecting pig-breeding which is a major activity on Kassa island. Human cases of African trypanosomiasis (HAT) were reported from all three of the inhabited islands from the 1940s, but have not been reported there in recent years [1]. By contrast, the nearby mainland area - especially the

\footnotetext{
* Correspondence: philippe.solano@ird.fr

${ }^{3}$ IRD, UMR IRD-CIRAD 177, CIRDES Bobo-Dioulasso BP 454, Burkina Faso Full list of author information is available at the end of the article
}

littoral mangrove region - represents one of the currently most active areas for HAT transmission [2-5].

Comparison of tsetse from the Loos islands with conspecifics from the nearby mainland areas indicated a low rate of genetic exchange between the three islands [6] and an apparently high degree of genetic separation between the island populations and those of the mainland [7]. The two uninhabited islands - Corail and Blanche - did not harbour tsetse [1]. This invited the possibility of a programme designed to eradicate the flies from the entire archipelago following an area-wide strategy [8] addressing an apparently isolated target population to avoid the risk of reinvasion. If successful, such a programme would offer sustainable protection to the local communities - both from the tsetse nuisance and potential for human and animal trypanosomiases

\section{Biomed Central}


transmission - and would potentially stimulate additional economic activities (particularly increased pigrearing and tourism). The programme would also serve as a test-bed for tsetse eradication within the context of the African Union PATTEC initiative [9-11]. In addition, the programme would serve as a training centre for the national control team, and serve to illustrate the feasibility of tsetse eradication in West Africa even under conditions deemed highly suitable for the flies (and in the face of perennial socio-political difficulties).

After baseline data collection (see details in [1]) tsetse control began on the Loos islands in 2006. Here we present results of the first phase leading to a $100 \%$ reduction in apparent tsetse densities in the sentinel traps used for monitoring.

\section{Methods}

\section{Study area}

The Loos islands are a small archipelago of five islands totalling some $20 \mathrm{sq}$. $\mathrm{km}$ off the coast of Guinea Conakry, West Africa. The two largest islands, Fotoba and Kassa, are each about $10 \mathrm{Km}$ long but rarely more than $1 \mathrm{Km}$ width, with maximum altitude at 162 masl. The nearest to the mainland (Kassa) is about 4-5 km from the Kaloum peninsula of Conakry. Three of the islands - Kassa, Fotoba, Room - are inhabited, with a total population of about 8000 mainly involved with fishing, agriculture (cassava, palm trees, mangoes) and tourism, although bauxite mining was also important during 1950-70. Pig breeding is also an important secondary economic activity in Kassa, with the pigs generally exported to Conakry. The vegetation of the islands is mainly degraded Guinean savannah on the rocky areas, secondary forests in the fallow areas, and vergers of palms (Elaeis guineensis) and mango trees; annual rainfall is around $4000 \mathrm{~mm}$.

\section{Tsetse Population Baseline data and Monitoring}

For baseline data collection and subsequent monitoring of the tsetse population densities, a total of 40 sentinel traps were set up on the 3 islands during 2005-6 (20 in Kassa, 18 in Fotoba, 2 in Room). This number was doubled in Kassa and Room from July 2009. These traps were all of the unbaited Vavoua type, and their GPS coordinates were recorded in order to be sure to place them at the same locations for all surveys. Entomological surveys for monitoring were implemented every 3 months, this agenda being adapted to seasons and/or local conditions. For each monitoring survey, traps were left during 3 consecutive days with daily harvest of the cages and counting of the tsetse.

\section{Control techniques}

According to the results of the baseline data collection, a combination of techniques was chosen that was specific to each island. A sequential strategy was implemented: the control began on Kassa in October 2006, in Room in April 2007, then in Fotoba in November 2007. The underlying control strategy was to deploy all potential control methods that could be made available at relatively low cost - including the unimpregnated Vavoua traps for monitoring population density, similar traps and black/blue/black targets impregnated with deltamethrin, impregnated netting deployed around the pig-pens (traps, targets and netting supplied by Vestergaard-Frandsen), insecticide pour-ons for treatment of the pigs (supplied by Bayer AH), and ultra-low dosage (ULD) fogging with cyfluthrin or deltamethrin in selected thickets (Swingtec Gmbh, HD Hudson Manufacturing Co., and Bayer CS). These techniques were applied in a phased approach, partly because of logistic questions affecting the supply of materials, but also because we wanted to gain an idea of the effects of these techniques alone and in combination.

In Kassa, where the baseline data had shown the highest densities of tsetse (probably due to pig rearing) a combination of four different techniques was implemented: the epicutanous insecticide treatment of pigs (pourons) and insecticide impregnated fencing around pig pens, together with Impregnated Traps and Targets (ITT), plus selective ULD fogging of vegetation thickets. In Room and Fotoba, livestock were too few to constitute important hosts for tsetse. In Room, the smallest island, ITT were deployed in April 2007, and followed with some ULD fogging. In Fotoba, only ITT were used to be able to know their specific impact.

Details of each technique are as follows.

- impregnated traps and targets: Vavoua traps [12] and black/blue/black targets [13] factory impregnated with deltamethrin (as supplied by VestergaardFrandsen) were deployed as the main control measure. A preliminary spatial analysis had been conducted using a 2002 LANDSAT picture to select suitable sites for tsetse presence, based on the type and density of vegetation, and excluding unfavourable habitats (such as rocky hills). The impregnated traps and targets were initially placed at a density of $30 / \mathrm{sq} . \mathrm{km}$, but this was subsequently increased to 60/sq.km. During a preliminary assay in CIRDES, we had measured that the killing effect of the insecticide on these traps (measured as killing at least $50 \%$ of the tsetse in contact with the insecticide impregnated cloth) remained for 10 months (Additional file 1). Hence traps and targets were changed every year at the beginning of the dry season (October or November), since it is acknowledged that their efficacy during the rainy season is very poor - mainly due to grass growth reducing their visibility and thus 
attractiveness. It also has to be noted that tsetse control in the rainy season in Guinea is almost completely impossible due to the heavy rainfall $(4000 \mathrm{~mm}$ a year, from May to October) which makes access to control sites impossible.

- Pour-ons: After preliminary tests of the toxicity and efficacy of several products and formulations in CIRDES, Burkina Faso (unpublished data), Bayticol pour-on ( $1 \%$ flumethrin) was used 3 times at monthly intervals from oct-nov 2006. It was applied along the dorsal midline of about 1000 pigs each time, using a syringe, at the dose of $1 \mathrm{ml} / 5 \mathrm{~kg}$ of live weight (i.e. $2 \mathrm{mg}$ a.i. per $\mathrm{kg}$ ) (Figure 1). The Bayticol pour-on tested in similar conditions at CIRDES had a persistency ( $>50 \%$ of tsetse mortality) of about 20 days (see Additional file 2). The absence of acute toxicity was checked on 104 pigs in farms of Bobo Dioulasso, Burkina Faso. No adverse effects were observed, except moderate pruritus when applied to pigs infested with scabies (data not shown).

- impregnated fences: these consisted of $1 \mathrm{~m}$ high netting factory-impregnated with deltamethrin (provided by Vestergaard-Frandsen) that were set around 97 pig pens (Figure 1, and Figure 2). Tsetse visiting these pig pens are knocked down as they touch the fence and then subsequently die [14]. Persistence of the Knock Down effect was estimated on a sample of the netting after 6 months by testing in experimental conditions at CIRDES (see Additional file 2).

- ULV fogging: ground-spraying by ultra-low dose fogging was carried out selectively in areas that appeared to act as tsetse refuges - especially vegetation thickets where the targets were not very efficient. It consisted of 4 interventions every 3 weeks during 2009. For this, cyfluthrin was applied at a nominal rate of $2 \mathrm{~g} / \mathrm{ha}$, using two types of machine: 2 Swingfog SN50 thermal foggers (Swingtec $\mathrm{GmBH}$ ) and one Portapak and one Portastar cold foggers (Hudson Manufacturing). These were shoulder-carried either by two teams of two people walking, or applied from a small boat for costal thickets. Landsat $7 \mathrm{ETM}+$ images (resolution of $30 * 30 \mathrm{~m}$ ) were used to identify pathways for groundspraying that avoided human habitations; these pathways were then recorded as GPS tracks in order to avoid passing more than once or forgetting an area (see Figure 2). Particular attention was paid to wind direction and speed in this insular environment where this is governed by tide, and hours of spraying were organised accordingly.

In addition to these control techniques, we gave special attention to community discussions during each of the interventions. This has been essential to promote community understanding and acceptance of the

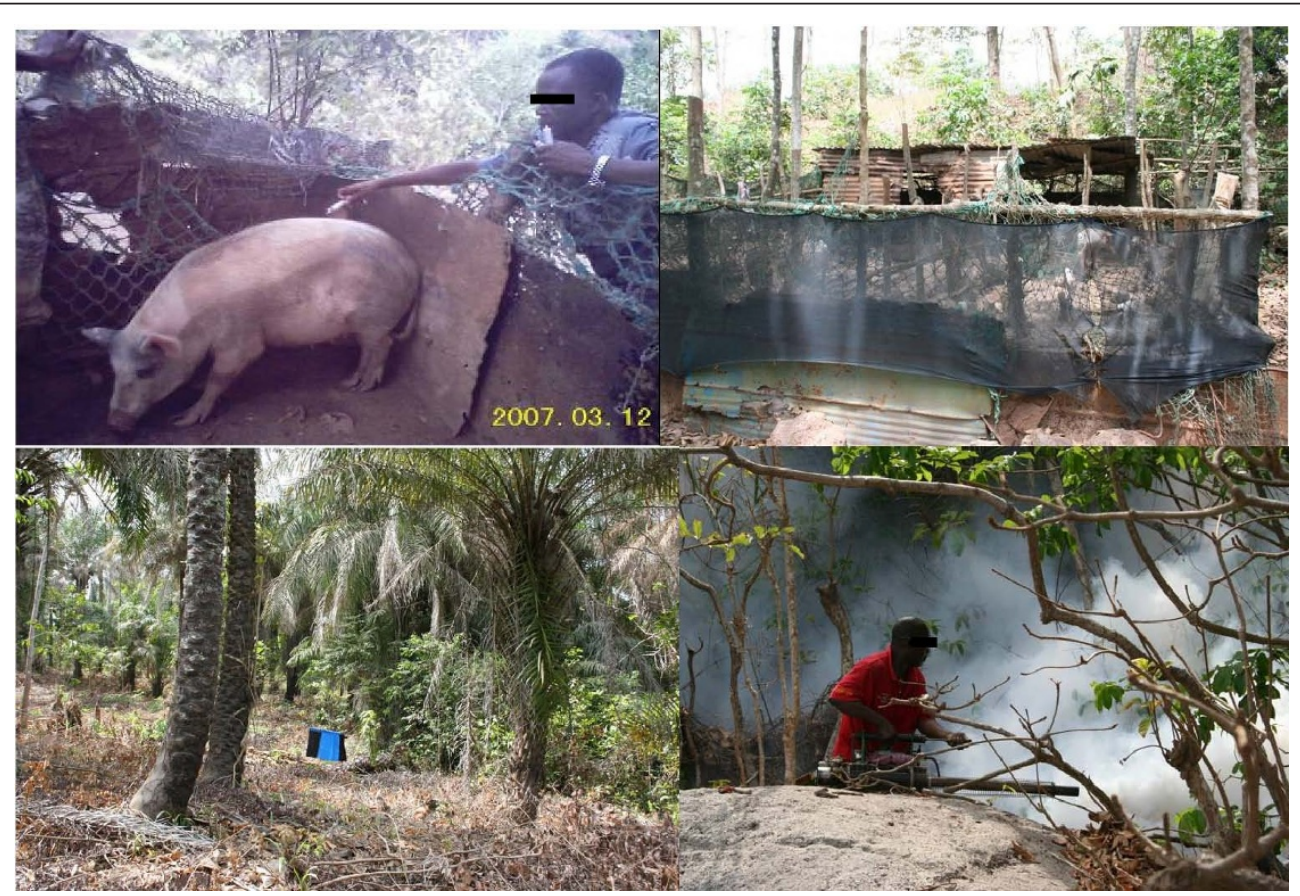

Figure 1 Pictures illustrating the different control techniques used against G. palpalis gambiensis on Kassa island, Guinea. From upper left to lower right are shown epicutaneous treatment using insecticide (pour on) on pigs, deltamethrin impregnated fences around pig pens, a deltamethrin impregnated black/blue/black target in a palm tree plantation, and cyfluthrin groundspraying using a Swinfog SN50. 


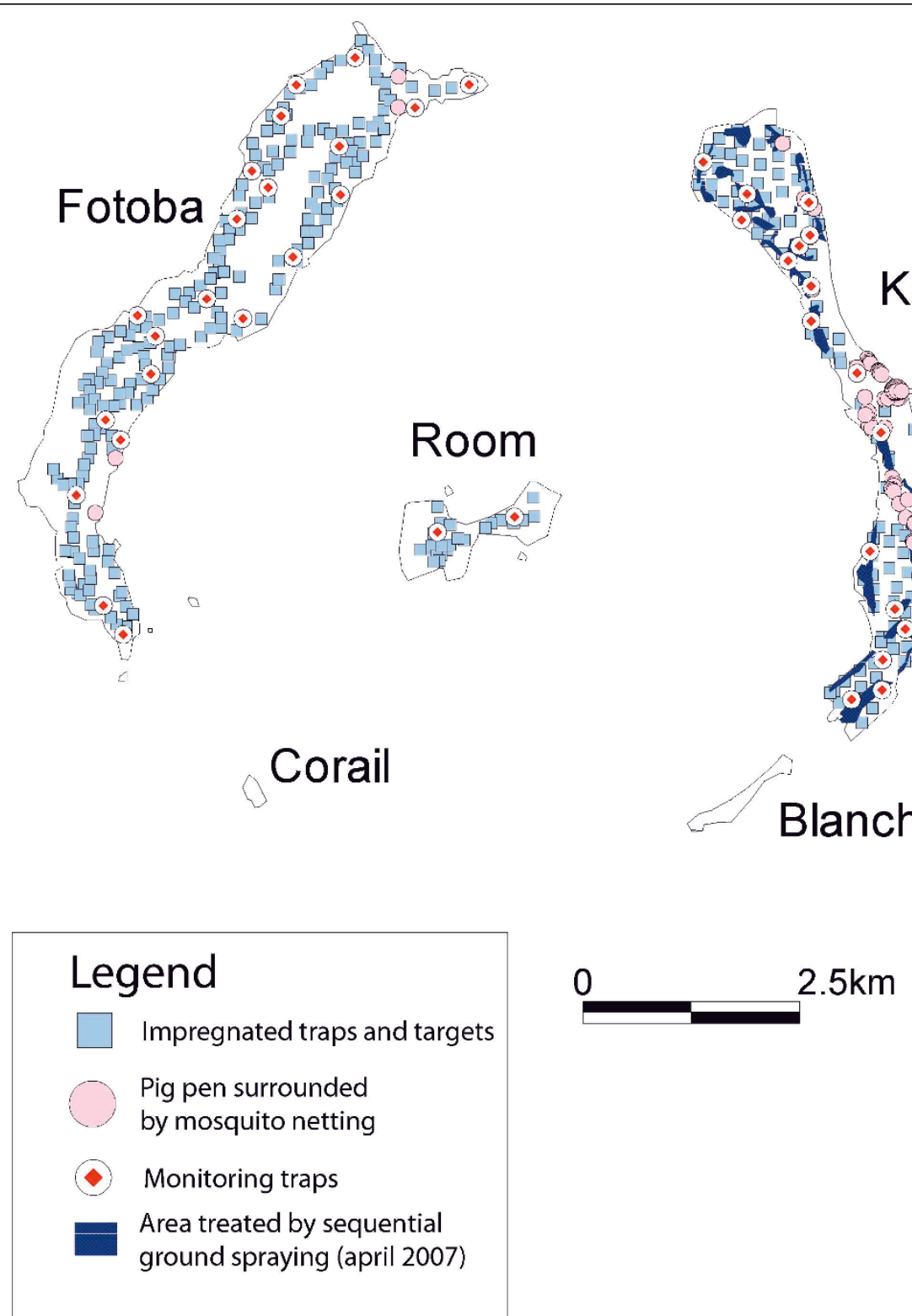

Figure 2 Combination and GPS location of control techniques applied on Loos islands. This map shows exact GPS locations of places where the different control techniques (see legend) were implemented on each of the three islands, together with the location of monitoring traps.

interventions (and decrease theft and losses of traps and targets) and also to promote active participation of the communities - especially with regard to their knowledge of tsetse refuges, and their help in creating tracks to have access to remote sites, maintenance of fields, regular burning of vegetation, and containment of animals,

\section{Results}

Starting densities in the sentinel traps in October 2006, at the beginning of the dry season and just before the implementation of control measures, averaged 10.33 flies/trap/day (FTD) (range 0 - 102) in Kassa, 3 FTD (range 0 - 6) in Room, and 1.16 FTD (range 0 - 14) in Fotoba. In July 2010, at the beginning of the rainy season, tsetse were no longer caught in any of the sentinel traps of the three islands, indicating an apparent reduction of $100 \%$ (Figure 3).

During the implementation of the control measures, tsetse densities varied according to each island and to the control measures implemented, as described below.

\section{Fotoba}

In Fotoba, control operations began in November 2007, with Impregnated Traps and Targets (ITT) at 30/sq.km 


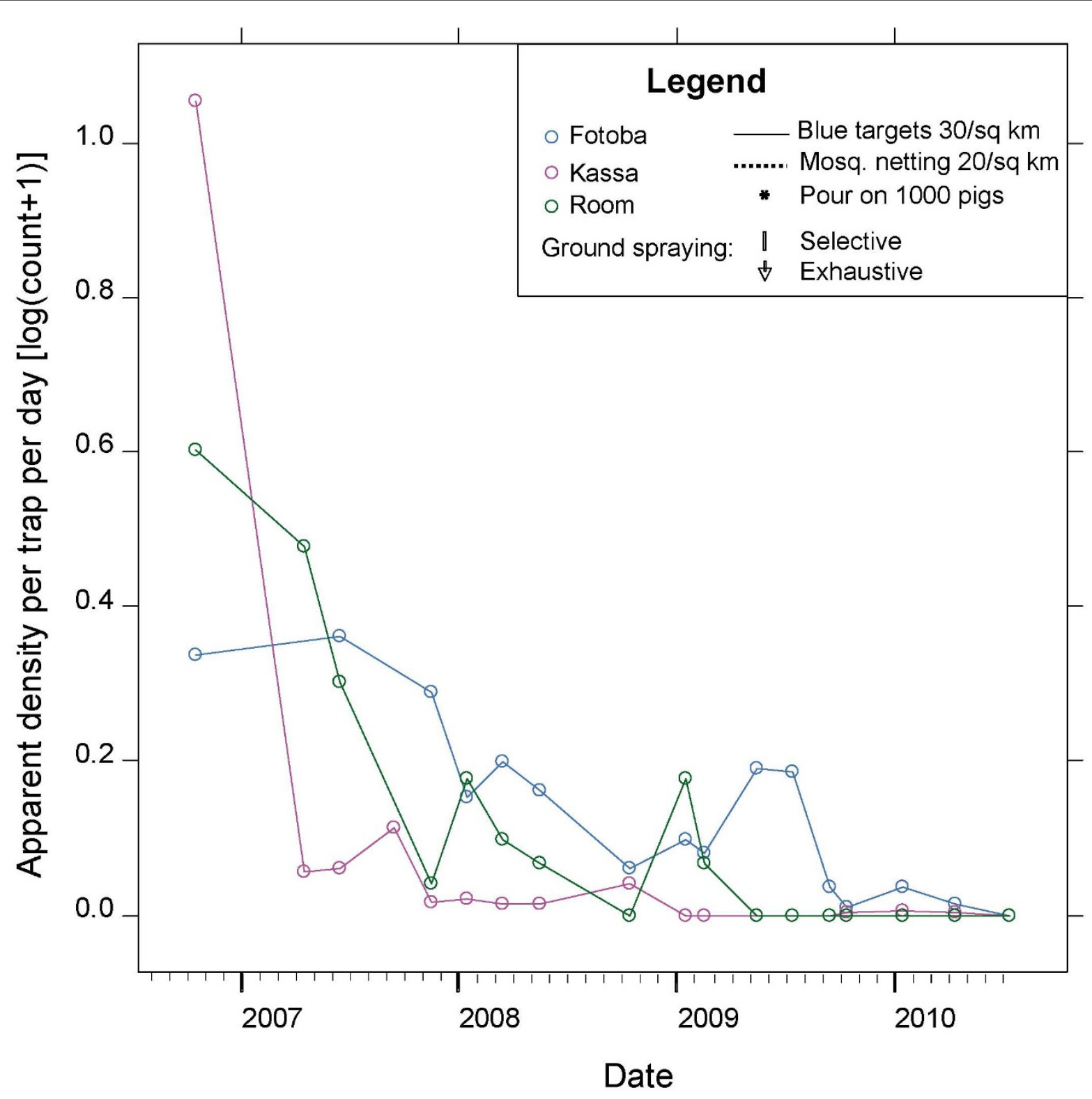

Fotoba

Kassa
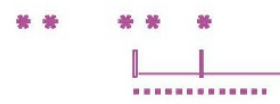

地监

Room

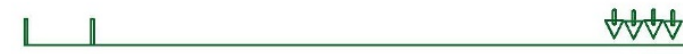

Figure 3 Overall evolution of G. $p$ gambiensis densities according to the different control operations applied on the three islands. The graph shows the evolution of tsetse densities ([log (count+1)], $Y$ axis) on the three islands according to each monitoring surveys (circles) ( $X$ axis showing year and months). Under the graph are detailed the different control methods implemented on each island and the date when they were implemented. 
being the only control measure implemented. Average tsetse density in Nov. 2007, just before the control interventions, was 0.94 FTD. Within the first six months, a reduction of $62 \%$ of the initial density was observed (Figure 3 ), but average fly density then remained stable (around 0.5 FTD) for a year, with only seasonal variations from March 2008 to May 2009 - as if a new population equilibrium had been reached following the initial control pressure. In March 2009, the density of ITT was thus doubled to $60 / \mathrm{sq}$. $\mathrm{km}$, leading to another decrease in average tsetse density during the following months, reaching 0.2 FTD (98\% suppression) in October 2009. This suppression level remained constant for several months, but slowly reached $100 \%$ in the sentinel traps by July 2010 .

\section{Room}

In Room, the control operations began in April 2007 with deployment of $30 \mathrm{ITT} / \mathrm{sq} . \mathrm{km}$. This was immediately followed by two selective ground spraying operations of the dry season refuges of tsetse in May and June. The result was a sharp decrease in tsetse densities on this island (97\% suppression from the initial density, after 6 months, Figure 3). This tsetse population density then remained fairly constant during the year, with a seasonal peak in January. The suppression then reached 100\% for the first time in October 2008, but some tsetse were then caught in January 2009. The density of ITT was thus doubled to 60/sq.km in March 2009 and after 4 successive cycles of groundspraying between February and April 2009, no more tsetse were caught on this island by the sentinel traps during 7 successive monitoring surveys of 3 consecutive days of trapping each.

\section{Kassa}

In Kassa, the initial densities were much higher than in the other islands ( 10 FTD in oct. 06, ranging from 0 to 102). The initial reduction in tsetse densities was very fast (98\% in 6 months), thanks to a combination of the four control techniques (see Figure 3 for entomological data, and Figure 1 for illustration of the control techniques). Nevertheless, tsetse could still be captured in the sentinel traps, although their densities were very low (in April 07 the average fly density was already 0.15 FTD), mainly in a limited area of the island, in the southern part harbouring dense vegetation. Therefore, four consecutive cycles of groundspraying were implemented in this area in 2009 and the number of ITT was doubled to $60 / \mathrm{sq} / \mathrm{Km}$ (see Figure 2). Actually, no flies were captured between January and September 2009 (5 consecutive surveys), and only a doubling of the number of sentinel traps allowed to trap again one tsetse in October 2009 at the end of rainy season, with a single fly in January and again in April 2010, showing that G. p. gambiensis can survive for a long time at very low densities, below the detection threshold of the original monitoring traps. Since July 2010 however, no further flies have been captured.

\section{Discussion}

This trial was designed to assess the feasibility of tsetse eradication using relatively low-cost methods, in an area of high biological and climatic suitability for G. palpalis gambiensis, but with the realistic constraints widespread in the tsetse infested areas of Africa, including lowbudget, logistic difficulties, climatic restrictions to access, and perennial uncertainty about the political situation. The word "eradication" here refers to its most recent definition as "the elimination of disease in a defined geographical area as a result of deliberate control efforts" [15], applying it here to tsetse presence rather than disease presence. The trial was prompted by studies of the tsetse populations that indicated negligible apparent gene flow between the mainland and island tsetse populations [7], and low rates of apparent gene flow between the different island populations [6], which suggested that if eradication were achieved on any or all of the infested islands then reinfestation from the mainland would be unlikely [10]. Overall, the results show that a rapid reduction in tsetse abundance was achieved within just a few months following the initial interventions (impregnated traps and targets, together with pour-ons and impregnated nets around pigpens in the case of Kassa island), and that this was perceived to be of great benefit by the local communities due to reduction in the biting nuisance. However, sustained reduction in tsetse abundance required continued intervention, supplemented by additional methods in specific areas.

At this stage, it would appear that tsetse have been eliminated from the islands, in the sense that no flies have been captured on any of the islands, despite intense sampling efforts, since July 2010. However, not catching tsetse in traps does not mean that they are no longer present [16]. Several reasons can account for this: tsetse can be out of the range of the trap attractiveness, especially in thick vegetation, and when unbaited traps are used (lack of attractiveness), or they may be attracted but still not enter the trap (lack of efficacy). It has been recently reported that only $\sim 15 \%$ of G. p. gambiensis attracted to a trap actually enter it [17]. For that reason, for monitoring purposes it may be more appropriate to use attractive devices that do not need capture systems such as cages, which reduce their efficacy. Targets coated with a sticky plastic (to catch tsetse which land on the target) as described by [18], or targets surrounded by electric grids ([19], or see also [17]) might do the job and would be interesting tools to monitor the success of control campaigns. It has also been suggested that tsetse could modify their behaviour 
during control operations. Amsler et al. [20] suggested that after a control campaign, tsetse were not attracted anymore by the type of traps used during control because of the selection pressure applied, and that there was a need to change the shape of the attractive device to catch the last flies. It has also been suggested that the efficiency of the traps could decrease with the increase of the reduction rate [21], because of density-dependant dispersal [22].

We can apply the model of Barclay \& Hargrove [16] to evaluate the probability (or risk) that tsetse were actually present although not captured through a given sampling effort (number of traps*days). In this model, the probability of observing a sequence of zero catches if in fact there are insects in the sampled area is given by:

$$
\mathrm{p}=\exp (-\mathrm{St} \sigma \lambda)
$$

where $S$ is the number of traps deployed in the total area, $t$ the number of days for which each trap is operated, $\sigma$ the trap efficiency and $\lambda$ the population density (number of insects/area of suitable habitat). For this model, the minimum number of flies in the sample area was set at 2 . The trap efficiency, defined as the probability that a trap catches a fly in an area of one square kilometre per day, was defined as 0.01 , according to estimates obtained for G. palpalis gambiensis by [23]. Applying this model to the tsetse capture data for Room would indicate a requirement for null captures over 19 consecutive sampling occasions in order to achieve a 95\% probability that tsetse were indeed absent; for Kassa and Fotoba, this would require null captures over a further 30 consecutive sampling occasions.

Setting insecticide impregnated targets and traps (ITT) at the initial rate of $30 / \mathrm{sq} \mathrm{km}$ resulted in a marked decrease in density of the targeted tsetse populations, as reported elsewhere for similar ITT densities [24,25], but was not enough to achieve complete suppression. To achieve the apparent $100 \%$ reduction in tsetse densities caught in the sentinel traps, the density of ITT had to be increased to $60 / \mathrm{sq}$. $\mathrm{km}$. Then, if supplemented by other techniques such as selective groundspraying, and/ or impregnated fences baited with live animals (i.e. pigs in the present case), the suppression was faster than if ITT were used on their own. Other works have reported densities of traps/targets even higher in forest environments where the visibility of the trap is low: up to 250/sq. km were used to control G. p. palpalis in Ivory Coast [26]. This is in contrast with areas such as austral Africa where densities of only 4 targets/sq. km [27,28] or even 1 target/sq. km [29] have enabled suppression of tsetse of the morsitans group. It is noteworthy that in this latter area, targets were baited with olfactory attractants (which are currently unavailable for tsetse of the palpalis group) and that the savannah vegetation is more open, allowing a better visibility of targets. Development of efficient olfactory attractants for tsetse of the palpalis group, which now seems feasible [30,17] would greatly assist in the control efforts.

For the Loos Islands, the next step will involve increasing the number of monitoring traps, or changing the traps to more efficient devices that do not need the flies to enter, in order to ascertain the likelihood that flies have been completely eliminated - i.e. when the probability of tsetse presence will be below 0.05 after which control operations will stop. A new monitoring effort would then be implemented 6 months after the end of the control period to allow a potential residual population to regenerate and to declare a definitive "eradication status" in case no further flies are being trapped, as has been done in Zanzibar for G. austeni [31]. It is noteworthy that, while waiting for this definitive eradication status for tsetse, disease transmission can already be considered to have been interrupted.

One of the additional results of this trial has also been to show that the total involvement of local teams is essential for the success of any eradication effort. The methods described here have necessarily been continually adapted to local conditions during the project, with the timing of activities adjusted from the original timetable due to various constraints (politicosocial events, logistic problems, lack of fuel, and so on). Staff of the National Control Programme (NCP) worked with the local communities to implement the control interventions. They asked for external technical support only when they felt it was necessary. The Guinean team was jointly constituted from the Ministry of Health and the Ministry of Livestock. The people involved were the coordinator (MC), the entomologist of the NCP (MSK), a veterinarian of the Direction of Livestock (OF), and four field assistants in entomology. Locally, additional manpower was recruited when necessary. In addition, there have been several field visits by collaborators based in CIRDES Burkina Faso and IPR Ivory Coast, either as technical support for training, or at progress meetings to discuss strategies, techniques and results.

\section{Conclusions}

The work will continue until total eradication has been obtained from Loos islands, since this seems to be the best guarantee for a sustainable protection of people and their domestic animals against human and animal trypanosomiases. At the same time the NCP will have to face other important challenges, such as implementing vector control in the sleeping sickness foci showing the highest prevalences, such as Dubreka and Boffa. Future projects aiming at eliminating sleeping sickness as a 
public health constraint will hopefully take advantage of the strengthening capacities of the Guinean team regarding vector control.

\section{Additional material}

Additional file 1: Supplementary file 1. Persistency of the knock-down effect of the blue fabric and mosquito netting used in Loos Island, against laboratory males G. p. gambiensis $6 \mathrm{H}$ after exposure in experimental conditions (95\% confidence intervals as vertical bars).

Additional file 2: Supplementary file 2. Persistency of the knock-down effect of Bayticol 1\% Pour on applied on pigs in experimental conditions against laboratory males G. p. gambiensis (95\% confidence intervals as vertical bars)

\section{Acknowledgements}

This work benefited from international collaboration through the Leverhulme Trust Tsetse Research Network (LTTRN) with support from the Ministry of Health and Ministry of Livestock of Guinea, French Ministère des Affaires Etrangères et Européennes (SCAC Conakry and FSP-REFS project), UE project TFCASS, Direction of CIRDES, and technical help from Wilfrid Yoni, Céné Bila, Fabien Dofini. We thank Bayer CS, Bayer AH, Vestergaard-Frandsen Aps, Swingtec Gmbh, and HD Hudson Manufacturing Co., for donations of equipment and material (with training in their use and maintenance), and we thank Fanny Bouyer for testing the toxicity of Bayticol pour-ons on pigs.

\section{Author details}

'Programme National de Lutte contre la THA, Ministère de la Santé, Conakry, Guinée. ${ }^{2}$ Cirad, UMR CIRAD-INRA CMAEE, ISRA-LNERV, Service de

Parasitologie, Dakar-Hann, Sénégal. ${ }^{3}$ RDD, UMR IRD-CIRAD 177, CIRDES BoboDioulasso BP 454, Burkina Faso. ${ }^{4}$ Direction de la Santé animale, Ministère de l'élevage, Conakry, Guinée. ${ }^{5}$ LSHTM (ITD), London WC1E7HT, UK.

\section{Authors' contributions}

PS, MC, CJS and JB conceived and designed the study, and critically revised the manuscript. MSK was the superviser and main component of all field operations, and drafted the manuscript. FC and MFO have been involved in all the GIS work, analysed the data, and contributed to the manuscript and figures. All authors have approved the final version of this manuscript.

\section{Competing interests}

The authors declare that they have no competing interests.

Received: 22 December 2010 Accepted: 10 February 2011

Published: 10 February 2011

\section{References}

1. Kagbadouno M, Camara M, Bouyer J, Hervouet JP, Courtin F, Jamonneau V, Jamonneau P: Tsetse elimination: its interest and feasibility in the historical sleeping sickness focus of loos islands, Guinea. Parasite 2009, 16:29-35.

2. Camara M, Kaba D, KagbaDouno M, Sanon JR, Ouendeno FF, Solano P: Human African trypanosomiasis in the mangrove forest in Guinea: epidemiological and clinical features in two adjacent outbreak areas. Med Trop 2005, 65:155-161.

3. Courtin F, Jamonneau V, Duvallet G, Garcia A, Coulibaly B, Doumenge JP, Cuny G, Solano P: Sleeping sickness in West Africa (1906-2006): changes in spatial repartition and lessons from the past. Trop Med Int Health 2008, 13:334-344.

4. Jamonneau V, Bucheton B, Kaboré J, Ilboudo H, Camara O, Courtin F, Solano P, Kaba D, Kambire R, Lingue K, Camara M, Baelmans R, Lejon V, Büscher P: Immune trypanolysis is a marker for $T$. b. gambiense contact: applications for diagnosis and surveillance of sleeping sickness in West Africa. PLoS Negl Trop Dis 2010.

5. Simarro P, Cecchi G, Paone M, Franco J, Diarra A, Ruiz J, Fèvre E, Courtin F, Mattioli R, Jannin J: The Atlas of human African trypanosomiasis: a contribution to global mapping of neglected tropical diseases. Int $J$ Health Geo 2010, 9:57.

6. Solano P, Ravel S, Bouyer J, Camara M, Kagbadouno MS, Dyer N, Gardes L, Herault D, Donnelly MJ, De Meeûs T: Population Structures of Insular and Continental Glossina palpalis gambiensis in Littoral Guinea. PLoS Negl Trop Dis 2009, 3(3):e392.

7. Camara M, Caro-Riano H, Ravel S, Dujardin JP, Hervouet JP, de Meeüs T, Kagbadouno M, Bouyer J, Solano P: Genetic and morphometric evidence for population isolation of Glossina palpalis gambiensis from Loos islands, Guinea. J Med Entomol 2006, 43:853-860.

8. Vreysen M, Robinson AS, Hendrichs J: Area-Wide Control of Insect Pests, From research to field implementation Dordrecht, The Netherlands, Springer; 2007, 789.

9. Kabayo J: Aiming to eliminate tsetse from Africa. Trends Parasito/ 2002, 18:473-475,

10. Schofield CJ, Patterson JS: Preparing for tsetse eradication. South Afr J Sci 2005, 101, p.116.

11. Schofield CJ, Kabayo JP: Trypanosomiasis vector control in Africa and Latin America. Parasites and Vectors 2008, 1:24.

12. Laveissière $C$, Grébaut $P$ : Recherches sur les pièges à glossines. Mise au point d'un modèle économique : le piège "Vavoua". Trop Med Parasitol 1990, 41:185-192.

13. Laveissière $C$, Couret $D$, Grebaut P: Recherche sur les écrans pour la lutte contre les glossines en région forestière de Cote d'Ivoire. Mise au point d'un nouvel écran. Cah ORSTOM Sér Ent Méd Parasitol 1987, 25:145-164.

14. Bauer B, Gitau D, Oloo FP, Karanja SM: Evaluation of a preliminary trial to protect zero-grazed dairy cattle with insecticide-treated mosquito netting in Western Kenya. Trop An Health Prod 2005, 38:31-36.

15. Enserink M: Global public health. Scientists' new eradication target: a word in their lexicon. Science 330:1738-1739.

16. Barclay HJ, Hargrove JW: Probability models to facilitate a declaration of pest-free status, with special reference to tsetse (Diptera: Glossinidae). Bull Ent Res 2005, 95:1-11.

17. Rayaisse JB, Tirados I, Kaba D, Dewhirst S, Logan J, Diarrassouba M, Omolo P, Solano P, Lehane MJ, Pickett J, Torr SJ, Esterhuizen J: Prospects for odour bait development to control vectors of Trypanosomiasis in West Africa, the tsetse flies Glossina tachinoides and G. palpalis s.I. PLoS Negl Trop Dis 2010, 4:e632.

18. Mohamed-Ahmed MM, Mihok S: Alighting of Tabanidae and muscids on natural and simulated hosts in the Sudan. Bull Ent Res 2009, 99:561-571.

19. Vale GA: Visual responses of tsetse flies (Diptera: Glossinidae) to odourbaited targets. Bull ent Res 1993, 83:277-289.

20. Amsler $\mathrm{S}$, Filledier J, Millogo R: Efficacité comparée de différents pièges pour la capture de Glossina tachinoides (Diptera : Glossinidae) au Burkina Faso. Revue Elev Méd Vét Pays trop 1994, 47:207-214.

21. Gouteux JP, Artzrouni M, Jarry M: A density-dependant model with reinvasion for estimating tsetse fly populations (Diptera: Glossinidae) through trapping. Bull Ent Res 2001, 91:177-183.

22. Bouyer J, Solano P, Cuisance D, Itard J, Frézil JL, Authié E: Trypanosomosis: Control methods. In Infectious and parasitic diseases of livestock. Edited by: Lefèvre PC, Blancou J, Chermette J, Uilenberg G. Éditions Lavoisier (Tec 2010:1936-1943.

23. Bouyer J, Seck MT, Sall B, Guerrini L, Vreysen MJB: Stratified entomological sampling in preparation of an area-wide integrated pest management programme: the example of Glossina palpalis gambiensis in the Niayes of Senegal. J Med Entomol 2010, 47:543-552.

24. Politzar $\mathrm{H}$, Cuisance D: An integrated campaign against riverine tsetse flies Glossina palpalis gambiensis and Glossina tachinoides by trapping and the release of sterile males. Insect Sci Appl 1984, 5:439-442.

25. Laveissière $C$, Couret $D$, Kienon JP: Lutte contre les glossines riveraines à l'aide de pièges biconiques imprégnés d'insecticides, en zone de savane humide. Cah O.R.S.T.O.M., sér Ent Méd Parasitol 1981, XIX:41-48.

26. Laveissière C, Penchenier L: Manuel de lutte contre la maladie du sommeil IRD Editions, Collection Didactiques, Paris, France; 2005.

27. Vale GA, Lovemore DF, Flint S, Cockbill GF: Odour-baited targets to control tsetse flies, Glossina spp. (Diptera: Glossinidae), in Zimbabwe. Bull Ent Res 1988, 78:31-49.

28. Willemse LPM: A trial of odour baited targets to control the tsetse fly, Glossina morsitans centralis (Diptera: Glossinidae) in west Zambia. Bull Ent Res 1991, 81:351-357. 
29. Dransfield RD, Brightwell R, Kyorkua C, Williams B: Control of tsetse fly (Diptera: Glossinidae) populations using traps at Nguruman, south-west Kenya. Bull Ent Res 1990, 80:265-276.

30. Omolo MO, Hassanali A, Mpiana S, Esterhuizen J, Lindh J, Lehane MJ, Solano P, Rayaisse JB, Vale GA, Torr SJ, Tirados I: Prospects for developing odour baits to control Glossina fuscipes spp., the major vector of human African trypanosomiasis. PLoS Negl Trop Dis 2009, 3:e435.

31. Vreysen MJ, Saleh KM, Ali MY, Abdulla AM, Zhu ZR, Juma KG, Dyck VA, Msangi AR, Mkonyi PA, Feldmann HU: Glossina austeni Diptera:Glossinidae) eradicated on the Island of Unguja, Zanzibar, using the sterile insect technique. J Econ Entomol 93:123-135.

doi:10.1186/1756-3305-4-18

Cite this article as: Kagbadouno et al:: Progress towards the eradication

of Tsetse from the Loos islands, Guinea. Parasites \& Vectors 2011 4:18.

Submit your next manuscript to BioMed Central and take full advantage of:

- Convenient online submission

- Thorough peer review

- No space constraints or color figure charges

- Immediate publication on acceptance

- Inclusion in PubMed, CAS, Scopus and Google Scholar

- Research which is freely available for redistribution

Submit your manuscript at www.biomedcentral.com/submit 